Shevchenko O., Petryk N. Dynamics of changes in the cellular composition of the focus of inflammation in secondary chronic inflammation with the introduction of mesenchymal stem cells. Journal of Education, Health and Sport. 2020;10(1):295-309. eISSN 2391-8306. DOI http://dx.doi.org/10.12775/JEHS.2020.10.01.033

https://apcz.umk.pl/czasopisma/index.php/JEHS/article/view/JEHS.2020.10.01.033

http://dx.doi.org/10.5281/zenodo.4424999

The journal has had 5 points in Ministry of Science and Higher Education parametric evaluation. § 8. 2) and § 12. 1. 2) 22.02.2019.

O The Authors 2020;
This article is published with open access at Licensee Open Journal Systems of Nicolaus Copernicus University in Torun, Poland

Open Access. This article is distributed under the terms of the Creative Commons Attribution Noncommercial License which permits any noncommercial use, distribution, and reproduction in any medium,

provided the original author $(\mathrm{s})$ and source are credited. This is an open access article licensed under the terms of the Creative Commons Attribution Non commercial license Share alike.
(http://creativecommons.org/icenses/by-nc-sa/4.0/) which permits unrestricted, non commercial use, distribution and reproduction in any medium, provided the work is properly cited.

The authors declare that there is no conflict of interests regarding the publication of this paper.

Received: 20.12.2019. Revised: 25.122019. Accepted: 31.01.2020.

\title{
DYNAMICS OF CHANGES IN THE CELLULAR COMPOSITION OF THE FOCUS OF INFLAMMATION IN SECONDARY CHRONIC INFLAMMATION WITH THE INTRODUCTION OF MESENCHYMAL STEM CELLS
}

\author{
O. Shevchenko, N. Petryk
}

Kharkiv National Medical University, Ukraine

Shevchenko Oleksandr, doctor of medical sciences, professor, Kharkiv National Medical University, professor of the Department of Pathological Physiology honorary named after professor D. O. Alpern, +380978299581, shevchenkoalexandr9@gmail.com, ORCID: 0000- 0001-6008-0362

Nataliia Petryk, Kharkiv National Medical University, $\mathrm{MD}, \mathrm{PhD}$ student of the Department of Pathological Physiology honorary named after professor D. O. Alpern, +380955077724, perfectgynecologist@gmail.com, ORCID: 0000-0001-6427-0155

\section{Abstract}

The study of the dynamics of the cellular composition of the inflammatory focus showed that an increase in the level of neutrophils, basophilic and eosinophilic leukocytes occurs during the observation period with a dominance in the central parts of the inflammation focus, aeosinophilia - similarly with a prevalence in the peripheral zones. This fact indicates the transition and the beginning of the proliferation phase. The results of our studies of the cellular composition of the inflammation focus in the dynamics of secondary chronic inflammation show that the use of MSCs leads to a decrease in the chronicity of the process. This proves the possibility of using MSCs to prevent chronic inflammation.

Key words: secondary chronic inflammation; focus of inflammation; mesenchymal stem cells. 


\section{Background}

Chronic inflammation is a pathological process characterized by an ongoing active inflammatory response and tissue destruction. A significant number of immune cells, including macrophages, neutrophils, and eosinophils, are involved directly or by producing inflammatory cytokines in chronic inflammation pathology [1].

One of the essential but little-studied factors influencing chronic inflammation regulation is mesenchymal stem cells (MSCs). The immunomodulatory and antiinflammatory properties of MSCs remain partially unclear. MSCs express a moderate level of the first class's main histocompatibility complex but do not represent the second class [2]. This phenotype is considered non-immunogenic, indicating that such a transplant to a halogen host will not require the use of immunosuppressants. Moreover, several studies show that MSCs have immunosuppressive properties by modulating specific $\mathrm{T}$ cells' functioning in vitro [3]. Some of these observations were made in vivo. An experimental model of graft-versushost disease was shown [4].

MSCs, which exist in almost all vascularized tissues, plays an essential role in regulating chronic inflammation [5]. Chronic inflammation is an unresolved problem in modern society that accompanies various conditions, such as type II diabetes, atherosclerosis, obesity, cancer, neurodegenerative diseases, etc. [6-10]. Various mediators are responsible for the immunomodulatory ability of MSCs, such as transforming growth factor $\beta$, indolamine 2,3-dioxygenase, induced nitric oxide synthase, and prostaglandin E2 [11]. These opportunities indicate great therapeutic potential for MSCs. Several studies have recently reported that MSCs can alleviate liver fibrosis and promote liver regeneration [12].

\section{Materials and methods}

The study was performed on 132 male laboratory rats weighing 200-220 g, aged 4-5 months, divided into 12 groups. The inflammatory pattern was chronic aseptic inflammation caused by intramuscular injection of $10 \mathrm{mg}$ of $\lambda$-carrageenan (Sigma-Aldrich $\mathrm{GmbH}$ ) into the right thigh. We used the minimum acceptable for statistical processing and obtaining reliable results conditional number of animals (6 per group) and the minimum sufficient to achieve the goals.

According to the standard method described, mesenchymal stem cells were isolated from the bone marrow of male rats [13 - 16]. Under sterile conditions, the epiphyses of the femur of adult rats were removed, and the bone marrow was washed from the cerebrospinal canal using a syringe with Hanks' solution (Biowest, France). Cells were centrifugated (900 g, $10 \mathrm{~min}$ ). Mononuclear cells were isolated by centrifugation in a Ficoll-Hypaque solution. The 
cells were resuspended in saline at a concentration of $1.0 \times 106$ in $1 \mathrm{ml}[17,18]$. The total number and content of living cells were counted in a hemocytometer by staining with $0.2 \%$ trypan blue solution (JanssenChemica, Belgium).

MSCs were introduced into the area of carrageenan inflammation in rats at a dose of $0.5 \mathrm{ml}(1-2$ million cells $)$ in isotonic sodium chloride solution once a day with $\lambda$ carrageenan.

The control of the usual course of inflammation was intact rats - 6 animals, and rats injected with MSCs without causing inflammation (6 animals).

In the detailed dynamics of inflammation, from 6 o'clock to the 28th day, the dynamics of changes in the inflammatory focus's cellular composition was studied.

The obtained results were processed using the Student's t-test.

\section{Results and discussion}

In the inflammatory infiltrate of the muscle tissue of the thigh in the groups of natural inflammation and inflammation on the background of MSC administration, the number of neutrophils (Fig. 1), compared with the groups intact control and control of the background of MSC administration without further inflammation, 6 hours after administration of the studied substances increases sharply in the center and on the periphery of the inflammatory focus. On the 1st day, observed increases in both groups of the study. In the group of natural inflammation, their peak occurs on the 2 nd day, and in the group of inflammation on the background of the introduction of MSC on the 1st day. Subsequent follow-up is characterized by a gradual decrease in the level of neutrophils: respectively, from the 3rd day in the group of natural inflammation and the 2nd day - in the group of inflammation on the background of the introduction MSCs. In the group of natural inflammation in all periods of observation, the number of neutrophils in the center of the focus slightly exceeds their number at the periphery. A similar situation occurs in the group of inflammation on the background of the introduction of MSCs from 6 o'clock to 10 o'clock. In the future - the level of neutrophils in the same (minimal). This is probably due to a change in the qualitative cell composition and the liquefaction of the central departments' inflammatory infiltrate. 


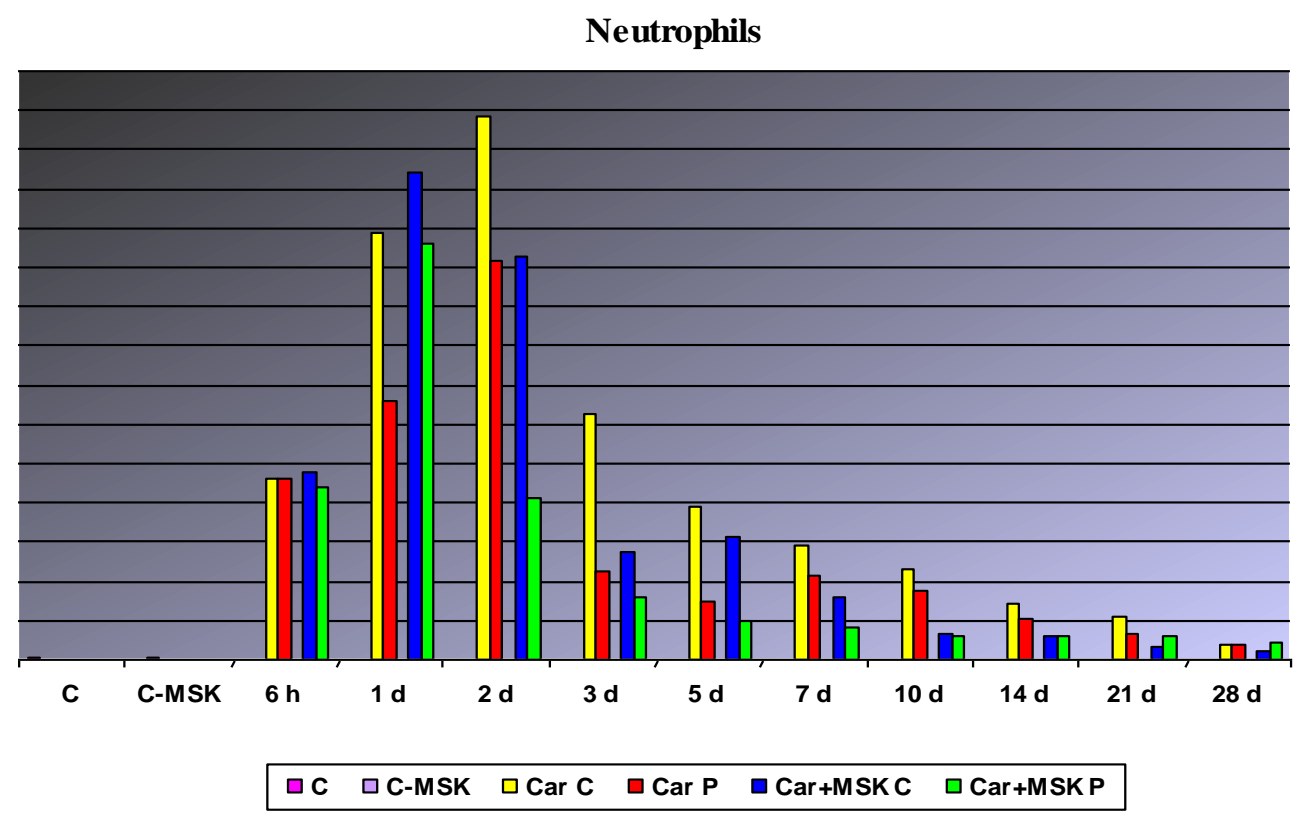

Fig. 1. The content (amount) of neutrophilic leukocytes in the center and on the periphery of the inflammatory focus depending on the observation period. C- intact control, C-MSK - control on the background of MSC injection without further induction of inflammation, Car+MSK - inflammation on the background of MSCs, Car C - center of the focus of natural inflammation, Car P - peripheral areas of the focus of natural inflammation, Car+MSK C - center of the focus inflammation on the background of MSCs, Car+MSK P peripheral areas of the focus of inflammation on the background of MSCs.

The change in the level of basophilic leukocytes (Fig. 2) in the studied groups' inflammatory focus is also characterized by an increase in their number at the 6th hour of observation. The maximum value is observed on the 2 nd day in the group of natural inflammation with a subsequent decrease from the 3rd day. In the group of inflammation on the background of the introduction of MSCs, the peak of increase occurs on the 1st day, and then there is a decrease in their number. There is also a slight predominance of basophils at the periphery of the inflammatory infiltrate in the group of natural inflammation during the observation period 14-28 days, which may be associated with a decrease in cell density in the center of the inflammatory focus. 


\section{Basophils}

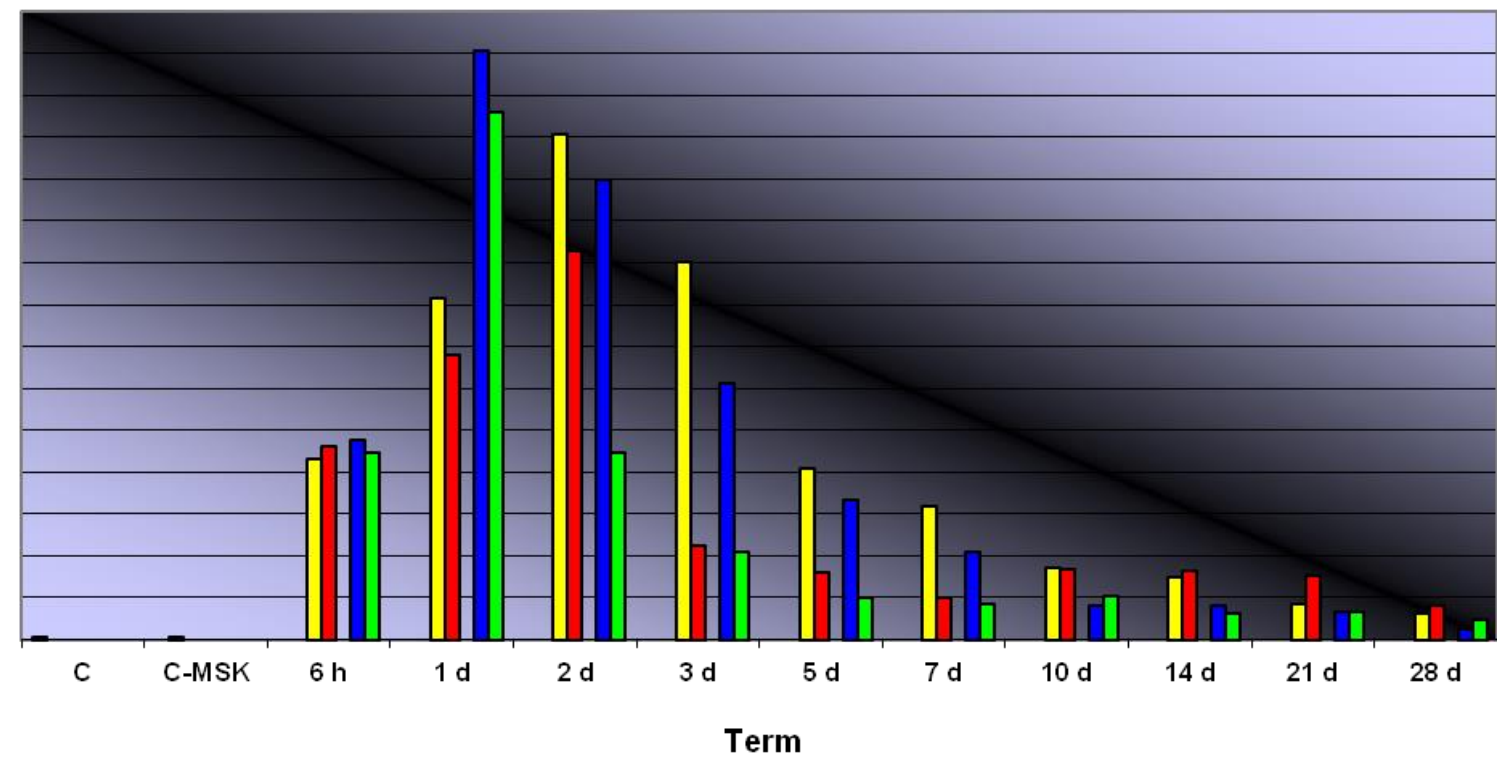

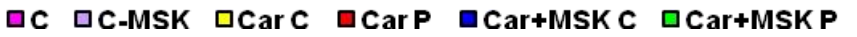

Fig. 2. The content (amount) of basophilic leukocytes in the center and on the periphery of the inflammatory focus depending on the observation period. C- intact control, C-MSK - control on the background of MSC injection without further induction of inflammation, Car+MSK - inflammation on the background of MSCs, Car C - center of the focus of natural inflammation, Car P - peripheral areas of the focus of natural inflammation, Car+MSK C - center of the focus inflammation on the background of MSCs, Car+MSK P peripheral areas of the focus of inflammation on the background of MSCs.

The highest number of eosinophilic leukocytes (Fig. 3) in both study groups occurs on the 1st day of observation. In the future, the level of eosinophils gradually decreases. In this case, starting from the 3rd day of the study, eosinophils in both groups are mainly localized on the periphery of the inflammation site. Interestingly, on the 28th day in the group of inflammation on the background of the introduction of MSCs, there is a rapid increase in their level. 


\section{Eosinophils}

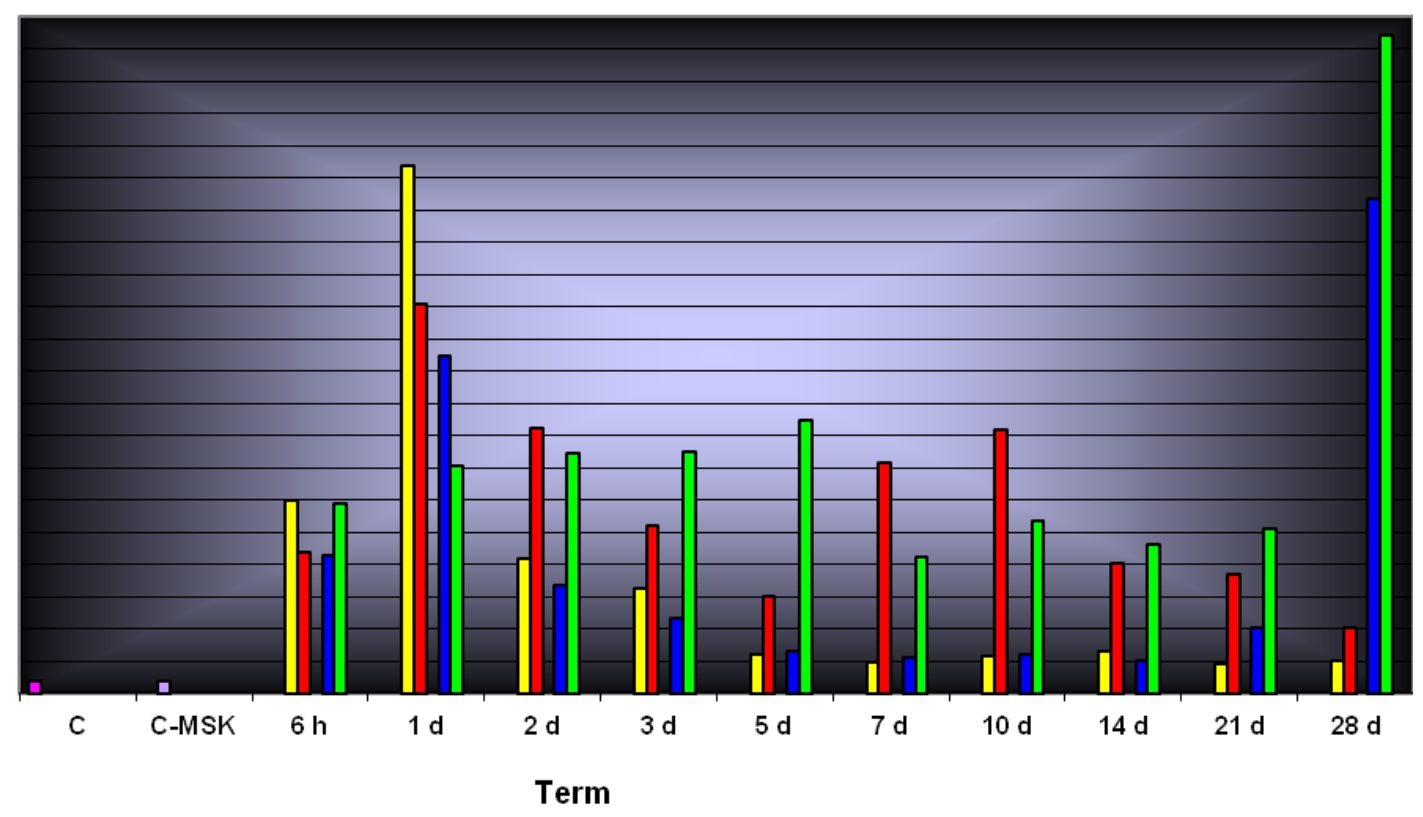

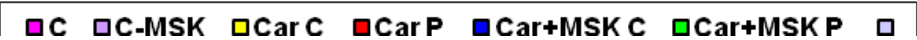

Fig. 3. The content (amount) of eosinophilic leukocytes in the center and on the periphery of the inflammatory focus depending on the observation period. C- intact control, C-MSK - control on the background of MSC injection without further induction of inflammation, Car+MSK - inflammation on the background of MSCs, Car C - center of the focus of natural inflammation, Car P - peripheral areas of the focus of natural inflammation, Car+MSK C - center of the focus inflammation on the background of MSCs, Car+MSK P peripheral areas of the focus of inflammation on the background of MSCs.

Changes in the level of monocytes (Fig. 4) are characterized by a gradual increase in their number in both groups, with a peak on the 5th day of the study. Later in the group of natural inflammation, there is a sharp decrease in their number, maintaining a higher periphery level. Although the group of inflammation on the background of MSC administration also has a decrease in monocytes' level (without a significant difference between the center and periphery), it exceeds that in the comparison group. 


\section{Monocytes}

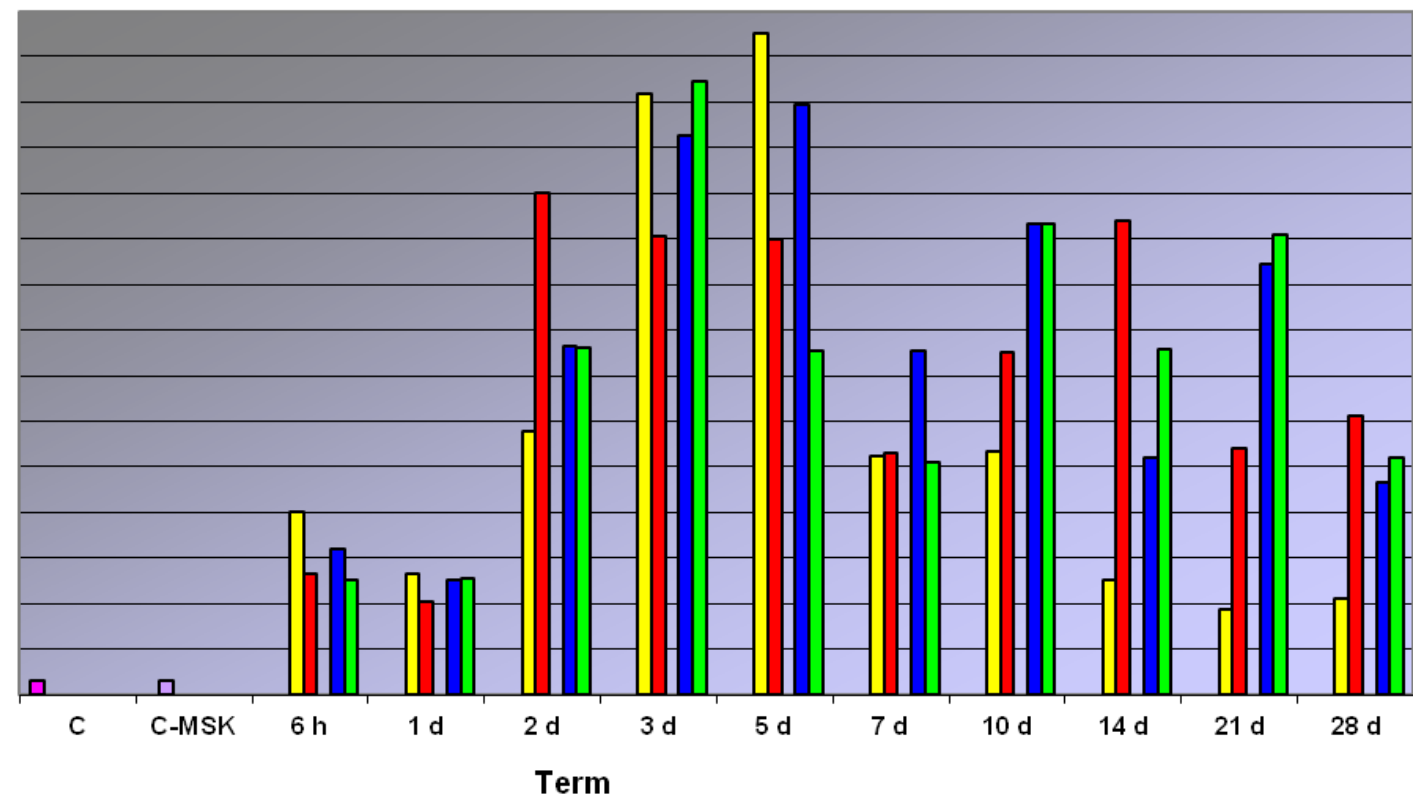

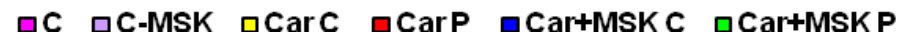

Fig. 4. The content (amount) of monocytes in the center and on the periphery of the inflammatory focus depending on the observation period. C- intact control, C-MSK - control on the background of MSC injection without further induction of inflammation, Car+MSK inflammation on the background of MSCs, Car C - center of the focus of natural inflammation, Car P - peripheral areas of the focus of natural inflammation, Car+MSK C center of the focus inflammation on the background of MSCs, Car+MSK P - peripheral areas of the focus of inflammation on the background of MSCs.

The dynamics of changes in plasma cells' level (Fig. 5) is somewhat similar to changes in monocytes. Therefore, in the group of natural inflammation, there is a gradual increase in their number in both groups, with a peak on the study's 5th day. Later in the group of natural inflammation, there is a decrease in their number with a slightly higher level in the peripheral areas. In the group of inflammation on the background of MSC introduction, the peak increase in plasma cell levels is on the 2 nd day, and then there is a decrease with the lowest rate on the 7th day; also, starting from the 5th day, their number on the periphery exceeds the central areas. 


\section{Plasma cells}

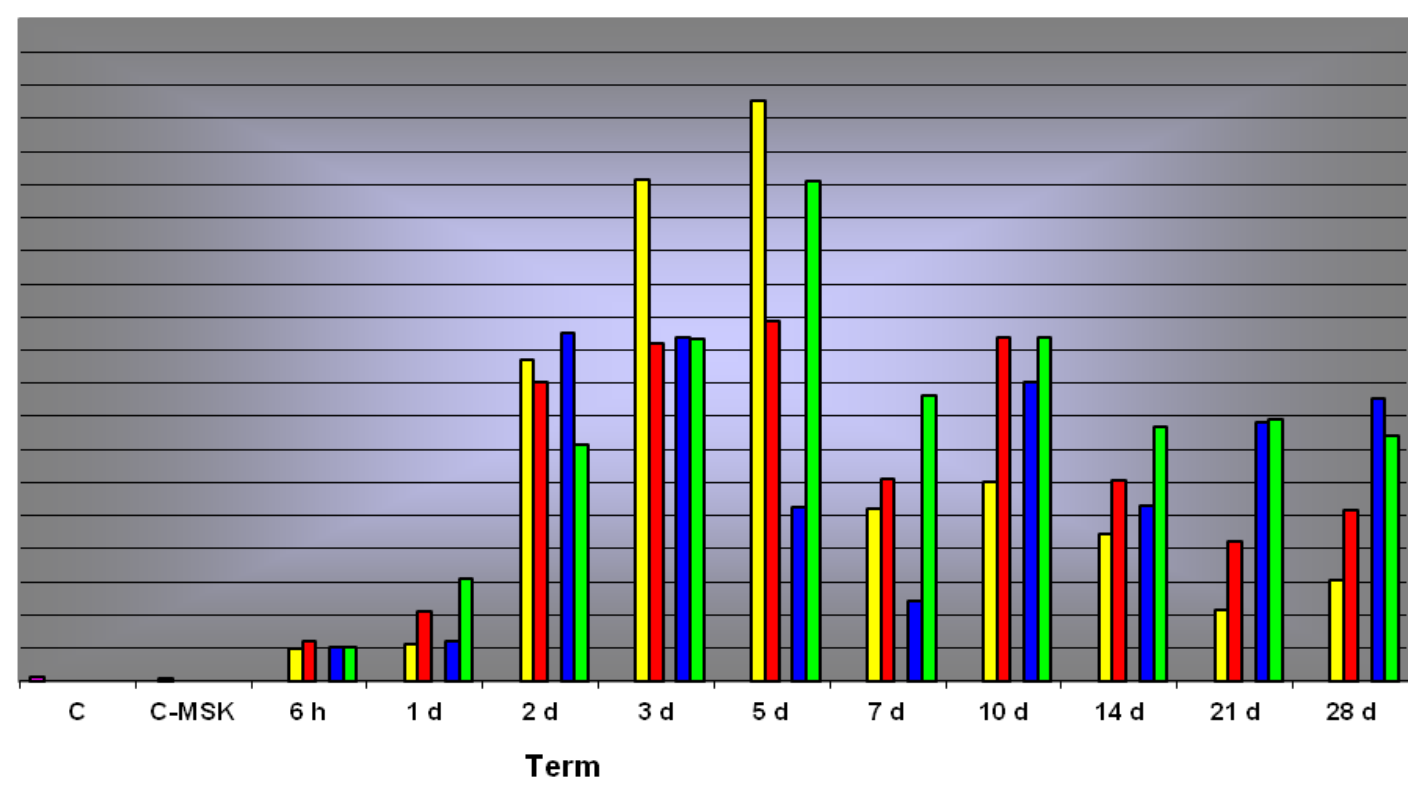

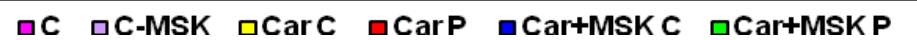

Fig. 5. The content (amount) of monocytes in the center and on the periphery of the inflammatory focus depending on the observation period. C- intact control, C-MSK - control on the background of MSC injection without further induction of inflammation, Car+MSK inflammation on the background of MSCs, Car C - center of the focus of natural inflammation, Car P - peripheral areas of the focus of natural inflammation, Car+MSK C center of the focus inflammation on the background of MSCs, Car+MSK P - peripheral areas of the focus of inflammation on the background of MSCs.

The dynamics of changes in the number of macrophages (Fig. 6) shows a synchronous increase in the number of cells in the center and on the periphery of inflammatory infiltrates up to the 7th day (peak). From the 10th day, remaining at a reasonably high level, they tend to decrease in both groups with dominance in the peripheral areas. 


\section{Macrophages}

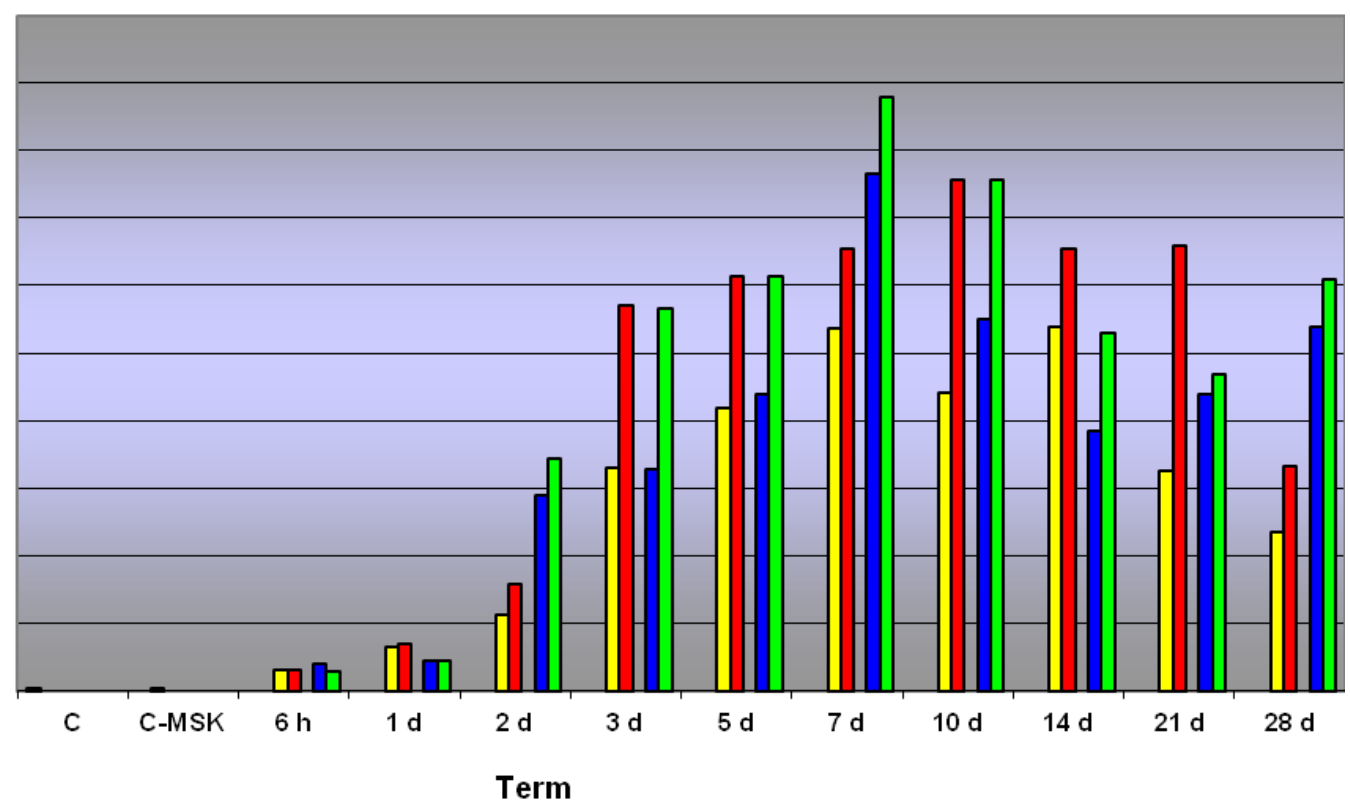

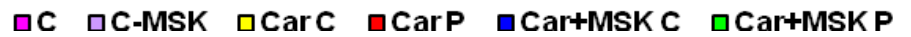

Fig. 6. The content (amount) of macrophages in the center and on the periphery of the inflammatory focus depending on the observation period. C- intact control, C-MSK - control on the background of MSC injection without further induction of inflammation, Car+MSK inflammation on the background of MSCs, Car C - center of the focus of natural inflammation, Car P - peripheral areas of the focus of natural inflammation, Car+MSK C center of the focus inflammation on the background of MSCs, Car+MSK P - peripheral areas of the focus of inflammation on the background of MSCs.

At all times of observation in both groups, tissue basophils (fig. 7) are found mostly on the inflammatory center's periphery. Their number in the central areas is not very different from the peripheral. Moreover, on the 3rd and fifth day, their content, especially on the periphery of inflammatory infiltrates, is higher in the group of inflammation on the background of the introduction of MSCs. 


\section{Tissue basophils}

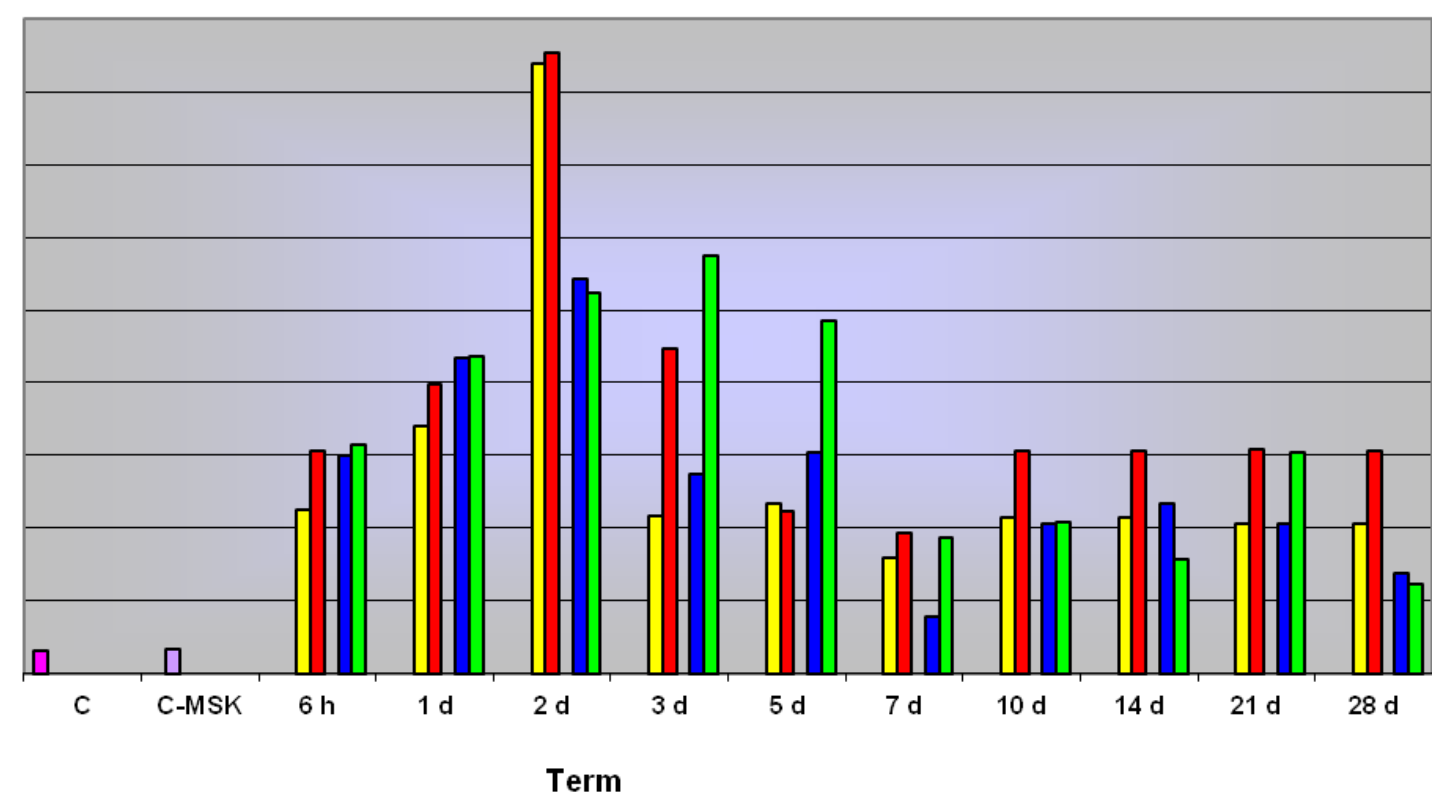

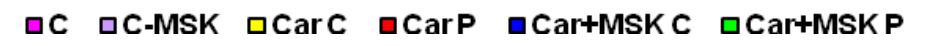

Fig. 7. The content (amount) of tissue basophils in the center and on the periphery of the inflammatory focus depending on the observation period. C- intact control, C-MSK control on the background of MSC injection without further induction of inflammation, Car+MSK - inflammation on the background of MSCs, Car C - center of the focus of natural inflammation, Car P - peripheral areas of the focus of natural inflammation, Car+MSK C center of the focus inflammation on the background of MSCs, Car+MSK P - peripheral areas of the focus of inflammation on the background of MSCs.

Cells of the fibroblastic series (Fig. 8) appear in the studied groups from the 2nd day (single), increase in number in the center, and more on the peripheral inflammatory focus. In the group of inflammation on the background of the introduction of MSCs on the 7th, 24th, and 28th day there is a sharp increase in their content, especially on the periphery. Whereas in the group of natural course of inflammation, there is a uniform increase in peripheral areas' prevalence. Cells of the fibroblastic series and the lymphoid-macrophage elements described above are also found in more significant numbers in the inflammatory group on the background of the introduction of MSCs. 


\section{Fibroblastic cells}

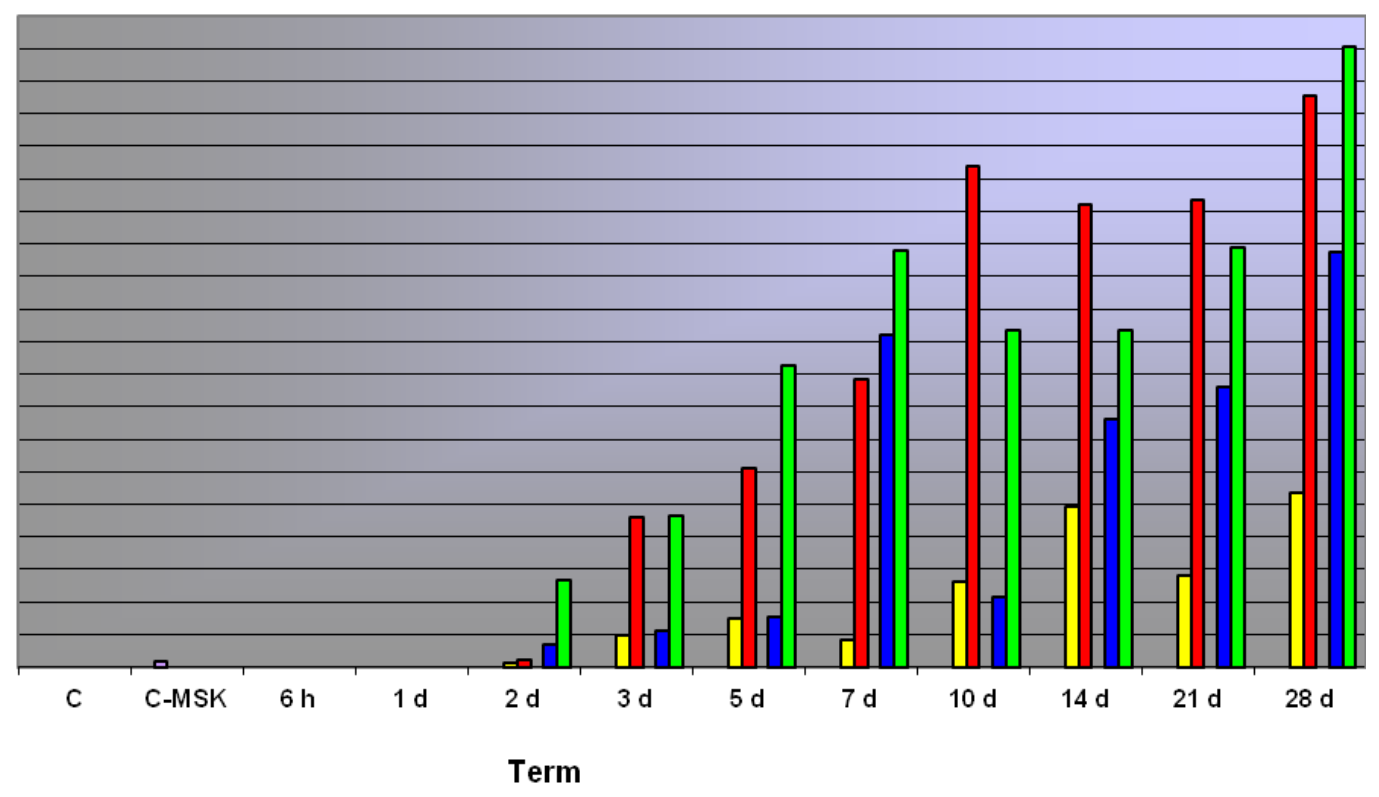

口C 口C-MSK 口CarC aCarP aCar+MSKC aCar+MSKP

Fig. 8. The content (amount) of fibrobastic cells in the center and on the periphery of the inflammatory focus depending on the observation period. C- intact control, C-MSK control on the background of MSC injection without further induction of inflammation, Car+MSK - inflammation on the background of MSCs, Car C - center of the focus of natural inflammation, Car P - peripheral areas of the focus of natural inflammation, Car+MSK C center of the focus inflammation on the background of MSCs, Car+MSK P - peripheral areas of the focus of inflammation on the background of MSCs.

On the 21st and 28th day of the study, the formation of giant multinucleated cells was observed in both groups (Fig. 9), which is more pronounced in the inflammatory group against the MSCs administration background. 


\section{Giant multinucleated cells}

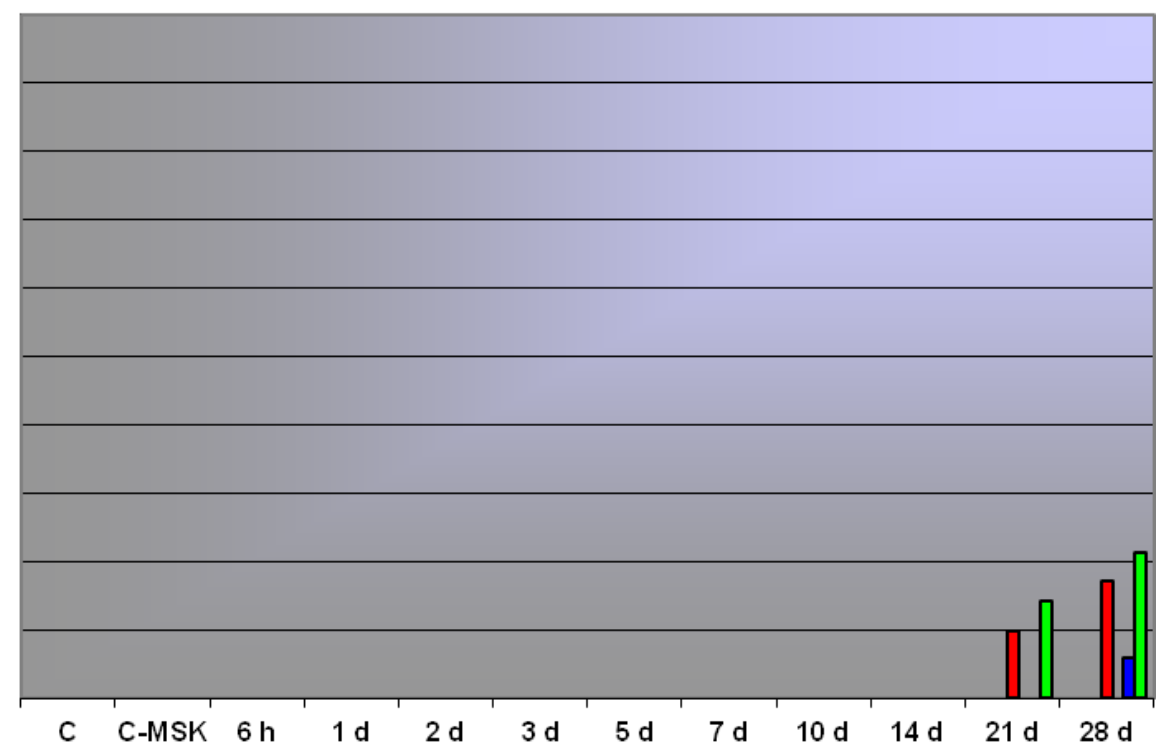

Term

aC aC-MSK aCarC aCarP aCar+MSK C aCar+MSK P

Fig. 9. The content (amount) of giant multinucleated cells in the center and on the periphery of the inflammatory focus depending on the observation period. C- intact control, C-MSK - control on the background of MSC injection without further induction of inflammation, Car+MSK - inflammation on the background of MSCs, Car C - center of the focus of natural inflammation, Car P - peripheral areas of the focus of natural inflammation, Car+MSK C - center of the focus inflammation on the background of MSCs, Car+MSK P peripheral areas of the focus of inflammation on the background of MSCs.

The study of the dynamics of changes in the cellular composition of the inflammatory focus revealed that increased the level of neutrophils, basal and eosinophilic leukocytes detected in the observation period of 6 years - third day with peaks of their content: neutrophils and basal profiles - on the 1st (distribution group at MSC input ) and the 2nd day (group of the natural course of inflammation), with dominance in the central parts of the inflammatory focus, eosinophils - on the 1st day and a slight decrease on the 2nd, and similarly with the transformation in the peripheral areas. Interesting is the fact of a different jump in the level of eosinophils in the inflammatory group on the background of the introduction of MSCs on the 28th day. 
The described cytological picture of the cell composition with the predominance of these cellular elements indicates the exudation phase of the inflammatory process.

From the 3 rd to the 5 th receipt in the cellular composition of infiltration based on a decrease in granulocytes' content, an increase in lymphocytes, monocytes, macrophages, plasma cells, tissue base filters, fibroblastic cells is observed. This fact indicates the transition and the beginning of the proliferation phase. The highest concentration of these elements is generally reflected in the peripheral zones in both studied groups. It is revised in the distribution group against the background of the introduction of MSCs. We can talk about the preparation of the processes of proliferation and organization in the peripheral areas, especially in the distribution group on the introduction of MSCs.

Fibroblastic cells, lymphoid-macrophage elements in more significant numbers are found in the group of the distribution group based on the introduction of MSCs, on the 21st and 28th day of the study in both groups, created during the formation of giant multisensory cells, which has a more significant impact on the distribution group. MSC environment.

\section{Conclusions}

The results of our studies of the cellular composition of the inflammatory focus in the dynamics of secondary chronic inflammation show that the use of MSCs reduces the chronization of the process. This proves the feasibility of using MSCs to prevent chronic inflammation.

Prospects for further research related to the improvement of pathogenetic therapy and the prevention of chronic inflammation.

\section{References}

1. Steffens S, Winter C, Schloss MJ, Hidalgo A, Weber C, Soehnlein O. Circadian Control of Inflammatory Processes in Atherosclerosis and Its Complications. ArteriosclerThrombVasc Biol. $2017 \quad$ Jun;37(6):1022-1028. doi: 10.1161/ATVBAHA.117.309374. Epub 2017 Apr 27. PMID: 28450299.

2. Le Blanc K, Ringden O. Immunobiology of human mesenchymal stem cells and future use in hematopoietic stem cell transplantation. Biol Blood Marrow Transplant. 2005;11:321-334

3. Beyth S, Borovsky Z, Mevorach D, Liebergall M, Gazit Z, Aslan H, Galun E, Rachmilewitz J. Human mesenchymal stem cells alter antigen-presenting cell maturation and induce T-cell unresponsiveness. Blood. 2005;105:2214-2219

4. Dazzi F, Marelli-Berg F.M. Mesenchymal stem cells for graft-versus-host disease: close encounters with T cells. Eur J Immunol. 2008;38:1479-1482 
5. Shi Y, Hu G, Su J, Li W, Chen Q, Shou P, Xu C, et al. Mesenchymal stem cells: a new strategy for immunosuppression and tissue repair. Cell Res 2010;20:510-518.

6. Leitner DR, Frühbeck G, Yumuk V, et al. 2017. Obesity and Type 2 Diabetes: Two Diseases with a Need for Combined Treatment Strategies - EASO Can Lead the Way. ObesFacts.10(5):483-492. doi:10.1159/000480525

7. Boloker, Gabrielle et al. Updated statistics of lung and bronchus cancer in United States. 2018. Journal of thoracic disease vol. 10,3 (2018): 1158-1161. doi:10.21037/jtd.2018.03.15.

8. Sitarz, Robert et al. 2018. Gastric cancer: epidemiology, prevention, classification, and treatment. Cancer management and research vol. 10 239-248. 7. doi:10.2147/CMAR.S149619.

9. Chen, W.-W., Zhang, X., \& Huang, W.-J. 2016. Role of neuroinflammation in neurodegenerative diseases (Review). MolecularMedicineReports, 13(4), 33913396. doi:10.3892/mmr.2016.4948

10. Nathan, C., \& Ding, A. 2010. Nonresolving Inflammation.Cell, 140(6), 871882. doi:10.1016/j.cell.2010.02.029

11. Li W, Ren G, Huang Y, Su J, Han Y, Li J, Chen X, et al. Mesenchymal stem cells: HepatologyHepatology 26 a double-edged sword in regulating immune responses. Cell Death Differ 2012;19:1505-1513.

12. Zhang, Y., Cai, W., Huang, Q., Gu, Y., Shi, Y., Huang, J., Zhang, Y. (2013). Mesenchymal stem cells alleviate bacteria-induced liver injury in mice by inducing regulatory dendritic cells. Hepatology, 59(2), 671-682. doi:10.1002/hep.26670

13. Morrison SJ, Scadden DT. The bone marrow niche for haematopoietic stem cells. Nature. 2014;505(7483):327-334. doi:10.1038/nature12984.

14. SusanneKern, HermannEichler, JohannesStoeve, HaraldKlüter, KarenBieback. 2012. Comparative Analysis of Mesenchymal Stem Cells from Bone Marrow, Umbilical Cord Blood, or Adipose Tissue. StemCells 24(5):1294-1301.

15. Baldev R. Gulati, Rajesh Kumar, NiharikaMohanty, PawanKuma, Rajesh K. Somasundaram, Prem S. Yadav. 2013. Bone Morphogenetic Protein-12 Induces Tenogenic Differentiation of Mesenchymal Stem Cells Derived from Equine Amniotic Fluid. Cells Tissues Organs 2013;198:377-389 DOI: 10.1159/000358231

16. Kassis I, Zangi L, Rivkin R, Levdansky L, Samuel S, Marx G, Gorodetsky R. 2006. Isolation of mesenchymal stem cells from G-CSF-mobilized human peripheral blood 
using fibrin microbeads. BoneMarrowTransplant. 2006 May;37(10):967-76. PMID:16670702DOI:10.1038/sj.bmt.1705358.

17. K. Uchida, K. Urabe, K. Naruse, M. Ujihira, K. Mabuchi, and M. Itoman. 2007. Comparison of the cytokine-induced migratory response between primary and subcultured populations of rat mesenchymal bone marrow cells. J OrthopSci 12:484-492 DOI 10.1007/s00776-007-1159-5.

18. Sotiropoulou PA, Perez SA, Salagianni M, Baxevanis CN, Papamichail M. 2006. Characterization of the optimal culture conditions for clinical scale production of human mesenchymal stem cells. StemCells. 2006 Feb;24(2):46271.DOI:10.1634/stemcells.2004-0331. 